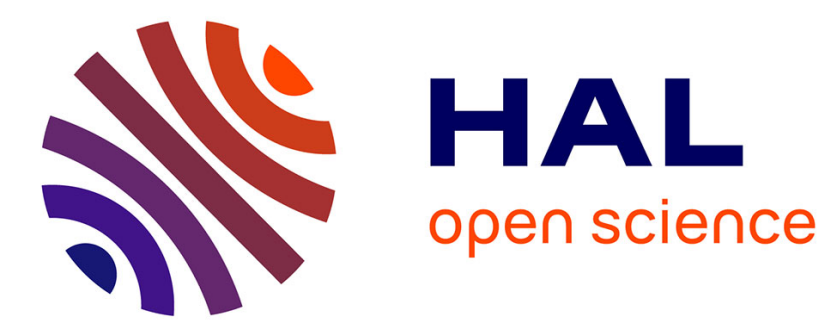

\title{
White Light Emission from a Zero-Dimensional Lead Chloride Hybrid Material
}

\author{
S. Elleuch, A. Lusson, S. Pillet, K. Boukheddaden, Y. Abid
}

\section{To cite this version:}

S. Elleuch, A. Lusson, S. Pillet, K. Boukheddaden, Y. Abid. White Light Emission from a ZeroDimensional Lead Chloride Hybrid Material. ACS photonics, 2020, 7 (5), pp.1178-1187. 10.1021/acsphotonics.9b01817 . hal-02987677

\section{HAL Id: hal-02987677 https://hal.science/hal-02987677}

Submitted on 11 Dec 2020

HAL is a multi-disciplinary open access archive for the deposit and dissemination of scientific research documents, whether they are published or not. The documents may come from teaching and research institutions in France or abroad, or from public or private research centers.
L'archive ouverte pluridisciplinaire HAL, est destinée au dépôt et à la diffusion de documents scientifiques de niveau recherche, publiés ou non, émanant des établissements d'enseignement et de recherche français ou étrangers, des laboratoires publics ou privés. 


\section{White light emission from a zero-dimensional lead-chloride hybrid material}

Slim Elleuch, "Alain Lusson, Sebastien Pillet, Kamel Boukheddaden, and Younes Abid

Dr. S. Elleuch, Prof. Y. Abid

Laboratoire de Physique Appliquée, Faculté des Sciences de Sfax, Université de Sfax, Route de Soukra km 3.5 BP 1171, 3018 Sfax, Tunisia.

E-mail : slimlpa@yahoo.fr, younes.abid@fss.rnu.tn

Prof. A. Lusson, Prof. K. Boukheddaden

Groupe d'Etudes de la Matière Condensée (GEMaC), UMR-CNRS 8653, Université de Versailles Saint Quentin En Yvelines, Université Paris-Saclay, 45 Avenue des Etats-Unis, 78035 Versailles, France.

Prof. S. Pillet

Laboratoire de Cristallographie, Résonance Magnétique et Modélisations

UMR-CNRS 7036, Institut Jean Barriol

Université de Lorraine, BP 239, 54506 Vandœuvre-lès-Nancy, France.

*Corresponding author: slimlpa@yahoo.fr

\section{Abstract:}

Organic-inorganic hybrid $(\mathrm{OIH})$ materials have emerged as high-performance class of light emitters, which can be used as phosphors for optically pumped white light-emitting diodes (WLEDs). Here, we report a new example of broadband white light (WL) emission from zero-dimensional lead chloride-based $\mathrm{OIH}$ material namely $(\mathrm{TAE})_{2}\left[\mathrm{~Pb}_{2} \mathrm{Cl}_{10}\right](\mathrm{Cl})_{2}(\mathrm{TAE}=$ tris(2aminoethyl) ammonium $\left(\mathrm{C}_{6} \mathrm{~N}_{4} \mathrm{H}_{22}\right)$ ). Single crystals of this compound and its corresponding ammonium salt TAE.HCl have been synthesized by slow solvent evaporation method at room temperature and were characterized by X-ray diffraction, optical absorption (OA) and photoluminescence (PL) measurements. The crystal structure shows an isolated lead chloride edge sharing bi-octahedra $\left[\mathrm{Pb}_{2} \mathrm{Cl}_{10}\right]^{6-}$ interacting with two $[\mathrm{TAE}]^{4+}$ cations and two $\mathrm{Cl}^{-}$ chlorine ions through multiple hydrogen bonds in a triclinic unit cell, which confers to this system its $0 \mathrm{D}$ character. Upon UV irradiation at $3.81 \mathrm{eV},(\mathrm{TAE})_{2}\left[\mathrm{~Pb}_{2} \mathrm{Cl}_{10}\right](\mathrm{Cl})_{2}$ shows a very broadband WL emission resulting from the overlapping of two peaks located at $2.07 \mathrm{eV}$ and $2.83 \mathrm{eV}$, respectively attributed to photoinduced free excitons confined in $\mathrm{Pb}_{2} \mathrm{Cl}_{10}$ inorganic bi-octahedra and the organic cations, respectively. When excited with a $4.66 \mathrm{eV}$ laser, the full 
width at half maximum of WL band luminescence reaches the unprecedented value of 1.25 eV (247nm), and exhibits the highest CRI value with 96 and a chromaticity coordinates closer to the reference white light. This was mainly attributed to light emission originating from some self-trapped excitonic states caused by structurally highly distorted inorganic subnetwork. The present results enrich the restricted family of hybrid perovskite WL emitters and highlight the importance of the 0D OIH materials for solid-state lighting applications.

Keywords: 0D hybrid material, Lead chloride, White light emission, FWHM, CRI.

Solid-state lighting, which presents an alternative solution to the inefficiencies of conventional lighting sources, has attracted great attentions in recent years. ${ }^{1}$ Realizing WL emission from light-emitting diodes (LEDs) is of particular interest for illumination applications. ${ }^{2}$ Different strategies for generating white light are well-known..$^{3,4}$ One can use (i) a combination of red, green, and blue LEDs in a single device; (ii) a blue LED connected to a single or two color conversion phosphors excited by the blue light, and (iii) a UV LED connected to three different phosphors, which emit in the blue, green, and red regions of the visible spectrum, respectively. While these techniques have been widely commercially accepted, the resulting devices suffer from a variety of inevitable drawbacks, such as the spectral overlap of the different constituting phosphors which can result in self-absorption and hence losses of emission efficiency and poor color stability. Especially, white light stability is often described by three main characteristics: (i) the Commission Internationale d'Eclairage "CIE": this is the most widely used method to describe the composition of any color in terms of three primaries (red-green-blue) coordinates; (ii) the Correlated Color Temperature "CCT": which indicates the temperature of a blackbody radiator that is most similar in chromaticity to the light being described, and (iii) the Color Rendering Index "CRI": this is a numerical measure of how true a color appears to the human eye when illuminated with a light source. It can be rated on a scale from 0 to 100 , where 100 is a true 
color representation. ${ }^{5}$ Therefore, a major aim in solid-state lighting research has been concentrated recently in the development of a single-component broadband WL emitting, highly luminescent, and photostable material which achieve the criteria imposed by the above mentioned characteristics. In this context, organic-inorganic hybrid $(\mathrm{OIH})$ materials represent an emerging class of crystalline photoactive materials, which have excellent solution processability with promising astounding physical properties for optoelectronics. ${ }^{6-9}$

While early investigations of OIH materials have been mainly focused on the structural and vibrational dynamics, they have been rediscovered over the past two decades and applied in promising optoelectronic fields, ${ }^{10-11}$ such as light emitting diodes (LED), ${ }^{12-16}$ Field Effect Transistors or thin film transistors (TFT), ${ }^{16-21}$ Solar Cells ${ }^{22-31}$ and Photovoltaics. ${ }^{32-38}$ Indeed, the inclusion of such materials into optoelectronics started with the pioneering works of Mitzi et al. ${ }^{16}$ who successfully assembled LED and TFT devices based on $\left(\mathrm{H}_{2} \mathrm{AEQT}\right) \mathrm{PbCl}_{4}$ and [(PEA) $\left.{ }_{2} \mathrm{SnI}_{4}\right]$ hybrid bidimensional (2D) systems, respectively. Shortly after that, we have witnessed an unpredicted breakthrough and quick evolution in the field of Solar Cells and Photovoltaics, with the realization of highly efficient solid-state hybrid solar cells based on hybrid material absorbers. In fact, recent implementations of OIH absorber with an organic hole conductor enabled Power Conversion Efficiencies (PCEs) greater than 20\%, ${ }^{29-31}$ and has been recognized as the "next big thing in photovoltaics". 32

More recently, the $\mathrm{OIH}$ perovskites have interestingly emerged as a highly promising class of light emitters, which can be used as phosphors for optically pumped White Light-Emitting Diodes (WLEDs). ${ }^{39}$ Broadband emissions with excellent color tunability and high photoluminescence quantum efficiency (PLQE) have been observed in many low-dimensional OIH materials. The first examples of broadband WL emission based on 2D lead bromide and lead chloride based $\mathrm{OIH}$ were reported by Dohner et al. ${ }^{40,41}$ on $(\mathrm{EDBE})\left[\mathrm{PbBr}_{4}\right]$ and $(\mathrm{N}-$ MEDA) $\left[\mathrm{PbBr}_{4}\right]$ and then by Yangui et al. ${ }^{42}$ on the OIH perovskites $\left(\mathrm{C}_{6} \mathrm{H}_{11} \mathrm{NH}_{3}\right)_{2}\left[\mathrm{PbBr}_{4}\right]$. 
Since these pioneering works, several research groups have reported new examples, ${ }^{43-68}$ achieving great values of the PLQY of $45 \%$ and $36 \%$ in 1D lead bromide ${ }^{68}$ and OD lead chloride ${ }^{66}$ hybrid materials. Moreover, broadband emission FWHM's (Full Width at Half Maximum) reached 0.9 and $0.95 \mathrm{eV}$ in more than one material, ${ }^{40,41,46}$ and the CRI exceeded in some case the commercial requirements for indoor illumination, ${ }^{41,47,61,64,65,67}$ where both "warm" and "cold" white light have been generated.

From all these results, some concluding remarks can be drawn. Except for some recently published works, ${ }^{48,51,58,59,67}$ most of the WL emission reported are based on 1D and 2D lead bromide or chloride hybrid materials. The origin of the broadband emission in these OIH was deeply discussed and associated mainly with the presence of a short-range electron-distortion coupling in the strongly deformable lattice which generates self-trapped carriers in the inorganic substructures. ${ }^{43,45,49,52,60}$ It was also evidenced that lowering the dimensionality of $\mathrm{OIH}$ materials from 2D to $1 \mathrm{D}$ to $0 \mathrm{D}$ enables a strong quantum confinement of the self-trapped excited states that produce highly efficient below-gap broadband luminescence and give efficient bluish white-light emissions. ${ }^{43,46}$ Also, these single-component white-light emitters have an easily controlled emission, better color-rendering capability, and reproducibility compared to the properties of the multicomponent phosphors. ${ }^{69}$ More importantly, it has been proven that the white-light emission intensity remains undiminished after continuous UV irradiation for 30 days under atmospheric conditions ( $\sim 60 \%$ relative humidity) ${ }^{49,60}$

In this work, we report the synthesis, crystal structure and photophysical properties of a new zero-dimensional organic lead chloride material, namely $(\mathrm{TAE})_{2}\left[\mathrm{~Pb}_{2} \mathrm{Cl}_{10}\right](\mathrm{Cl})_{2}(\mathrm{TAE}=$ tris(2aminoethyl) ammonium $\left(\mathrm{C}_{6} \mathrm{~N}_{4} \mathrm{H}_{22}\right)$ ), showing white light emission properties and exhibiting unprecedented values of $1.25 \mathrm{eV}(247 \mathrm{~nm})$ for the FWHM and CRI at 96 with chromaticity coordinates of $(0.30,0.33)$. The temperature-dependence of this emission was also undertaken, 
on single crystals of $(\mathrm{TAE})_{2}\left[\mathrm{~Pb}_{2} \mathrm{Cl}_{10}\right](\mathrm{Cl})_{2}$ and the corresponding ammonium salt TAE.HCl to investigate the origin and the thermal dependence of the WL performances of the material.

\section{Experimental section}

Single crystals of the $\mathrm{OIH}$ material $(\mathrm{TAE})_{2}\left[\mathrm{~Pb}_{2} \mathrm{Cl}_{10}\right](\mathrm{Cl})_{2}$ were synthesized by slow solvent evaporation at room temperature. Stoichiometric amounts of $\mathrm{PbCl}_{2}$ and Tris (2-aminoethyl) amine, $\left(\mathrm{NH}_{2} \mathrm{CH}_{2} \mathrm{CH}_{2}\right)_{3} \mathrm{~N}$, was stirred in aqueous solution of $\mathrm{HCl}$ and kept in the dark at room temperature. After two weeks, colorless platelets single crystals were formed. The crystal structure was determined using a supernova 4-circle micro-source diffractometer (Oxford Diffraction) equipped with a two-dimensional ATLAS detector, and using graphite monochromatized MoK $\alpha$ radiation $(\lambda=0.71073 \AA)$.

All optical measurements were performed on $(\mathrm{TAE})_{2}\left[\mathrm{~Pb}_{2} \mathrm{Cl}_{10}\right](\mathrm{Cl})_{2} \mathrm{HOI}$ and its corresponding ammonium salt TAE.HCl. The optical absorption (OA) spectra were measured at room temperature on spin-coated films using a conventional UV-Vis spectrophotometer (HITACHI, U-3300). Photoluminescence (PL) measurements were performed usinga JOBIN YVON HR 320 spectrophotometer under 266 and $375 \mathrm{~nm}$ excitation wavelengths, and with $50 \mathrm{~mW}$ excitation powers. For temperature dependence measurements, we used a Janis closed cycle cryostat. Photoluminescence excitation (PLE) was recorded at room temperature on a Fluoromax-4spectrofluorimeter equipped with a xenon lamp as anexcitation source.

\section{Crystal Structure}

X-rays diffraction experiments performed at room temperature (300K) show that $(\mathrm{TAE})_{2}\left[\mathrm{~Pb}_{2} \mathrm{Cl}_{10}\right](\mathrm{Cl})_{2}$ crystallizes as an $\mathrm{OIH}$ material in the triclinic space group $\mathrm{P}-1$ and the relevant crystallographic data are summarized in Table S1 of the supplementary material $(\mathrm{SM})$. As shown in Figure 1 , the crystal structure shows discrete $\left[\mathrm{Pb}_{2} \mathrm{Cl}_{10}\right]^{6-}$ entities, two $[\mathrm{TAE}]^{4+}$ cations and two $\mathrm{Cl}^{-}$ions packed in a triclinic unit cell. The $[\mathrm{TAE}]^{4+}$ cations are located in general positions with their three ammonium groups involved in $\mathrm{N}-\mathrm{H}$...Cl 
hydrogen bonds with the $\mathrm{Cl}$ atoms of $\left[\mathrm{Pb}_{2} \mathrm{Cl}_{10}\right]^{6-}$ groups and $\mathrm{Cl}^{-}$counter ions. In this structure, there exist two different $\left[\mathrm{Pb}_{2} \mathrm{Cl}_{10}\right]^{6-}$ groups, which are both located on an inversion center forming $\mathrm{Pb} 1$ and $\mathrm{Pb} 2$ edge-sharing bi-octahedra stacked along the crystallographic $\boldsymbol{a}$ direction. It presents structural strains considering the distortions of the two $\left[\mathrm{Pb}_{2} \mathrm{Cl}_{10}\right]^{6-}$ bioctahedra building blocks (see Figure S1-S5). These deformations involve modifications in $\mathrm{Pb}-\mathrm{Cl}$ bond lengths $(\mathrm{d})$ and $\mathrm{Cl}-\mathrm{Pb}-\mathrm{Cl}$ angles $(\alpha)$, and can be quantitatively evaluated using the followings formulas which introduce the octahedral elongation $\lambda_{\text {oct }}$ and octahedral angle variance $\sigma_{\text {oct }}^{2}:^{70}$

$$
\lambda_{\text {oct }}=\frac{1}{6} \sum_{\mathrm{i}=1}^{6}\left(\mathrm{~d}_{\mathrm{i}} / \mathrm{d}_{0}\right)^{2} \quad, \quad \sigma_{\text {oct }}^{2}=\frac{1}{11} \sum_{\mathrm{i}=1}^{12}\left(\alpha_{\mathrm{i}}-90\right)^{2}
$$

Here, $\mathrm{d}_{\mathrm{i}}$ are six independent $\mathrm{Pb}-\mathrm{Cl}$ bond lengths, $\mathrm{d}_{0}$ is the mean $\mathrm{Pb}-\mathrm{Cl}$ bond length and $\alpha_{\mathrm{i}}$ are the $\mathrm{Cl}-\mathrm{Pb}-\mathrm{Cl}$ angles. From the structural parameter in Table $\mathrm{S} 2$, the average values of $\mathrm{Pb} 1-$ $\mathrm{Cl}$ and $\mathrm{Pb} 2-\mathrm{Cl}$ bond lengths are 2.9012 and $2.9035 \AA$, leading to an octahedral elongation $\lambda_{\text {oct }}$ of 1.0011 and 1.0008, respectively. Furthermore, the corresponding octahedral angle variance, $\sigma_{\mathrm{oct}}^{2}$, are evaluated as 28.4 and $48.2^{\circ 2}$, respectively. Such values are very large when compared with reported ones $\left(5.98^{\circ 2}\right.$ for $(\mathrm{CyBMA})\left[\mathrm{PbBr}_{4}\right]^{54}, 8.28{ }^{\circ 2}$ for $\left(\mathrm{C}_{4} \mathrm{~N}_{2} \mathrm{H}_{14}\right)\left[\mathrm{PbCl}_{4}\right]^{63}$ and $14.2^{\circ 2}$ for $(\mathrm{EDBE})\left[\mathrm{PbI}_{4}\right]^{50}$ ) and reveal the existence high degrees of distortion for both inorganic entities. In this context, it is well known that such distortion plays a crucial role in the formation of self-trapped excitons, which are at the origin broadband emission. ${ }^{45,50,52,53}$ 

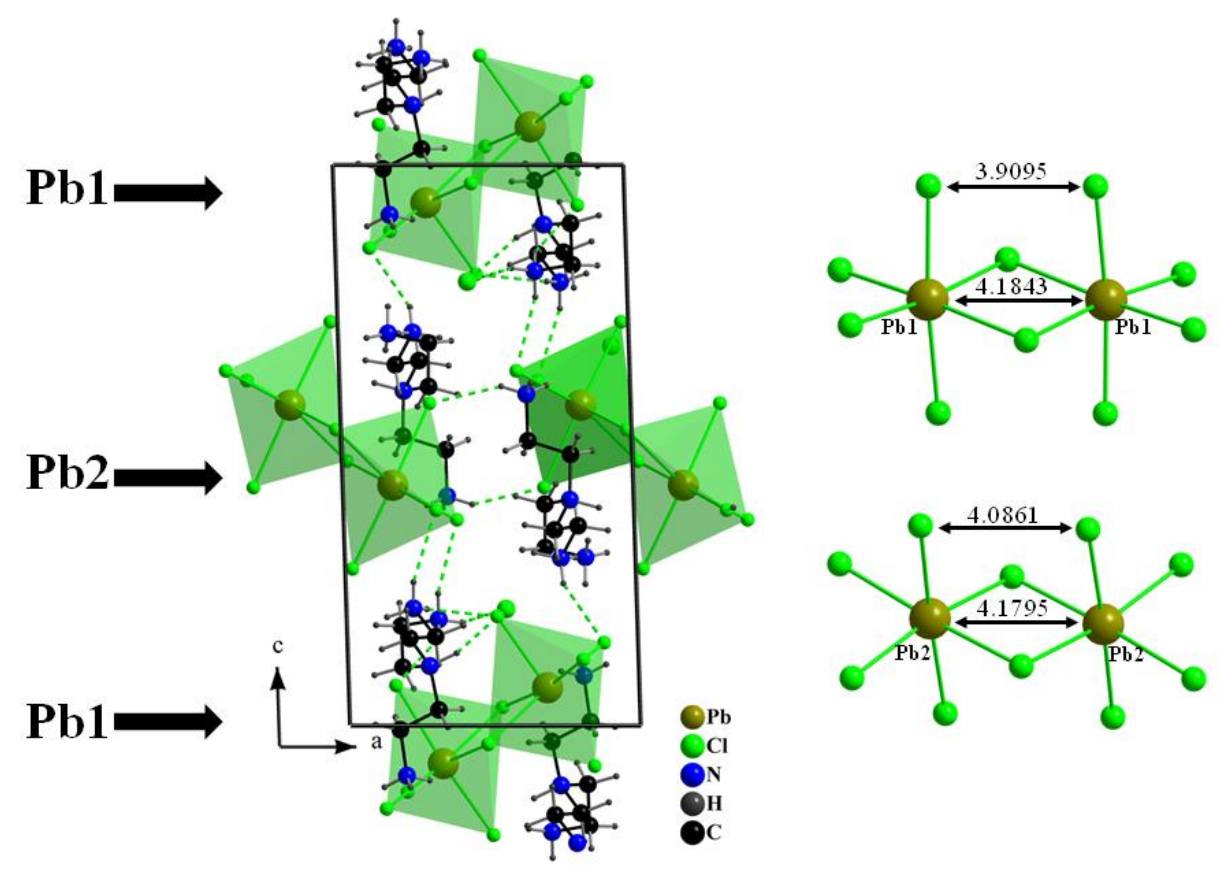

Figure 1. (Left) Crystal structure of the (TAE $)_{2}\left[\mathrm{~Pb}_{2} \mathrm{Cl}_{10}\right](\mathrm{Cl})_{2} \mathrm{HOI}$ material projected along the crystallographic b-axis. (Right) Two $\left[\mathrm{Pb}_{2} \mathrm{Cl}_{10}\right]^{6-}$ individual bi-octahedra showing different distortions values $(\mathrm{T}=300 \mathrm{~K})$.

\section{Photophysical Properties}

Figure 2 presents the room temperature photophysical properties of the $\mathrm{OIH}$ material $(\mathrm{TAE})_{2}\left[\mathrm{~Pb}_{2} \mathrm{Cl}_{10}\right](\mathrm{Cl})_{2}$ and its corresponding ammonium salt TAE.HCl. For the OIH material, the optical absorption spectrum (OA) (Figure 2(a)) shows a sharp absorption band at 3.77eV $(328 \mathrm{~nm})$ with a characteristic shape of exciton absorption, similar to that reported in lead chloride-based OIH materials, ${ }^{16,40,47,61-66}$ and attributed to the lowest excitons localized in the inorganic bi-octahedra $\mathrm{Pb}_{2} \mathrm{Cl}_{10}$. Moreover, the $\mathrm{OA}$ spectrum of the organic salt (TAE.HCl) shows an HOMO-LUMO gap of the organic cation at almost the same energy $(3.99 \mathrm{eV})$ and characterized by wide absorption band covering the entire of $\mathrm{Pb}_{2} \mathrm{Cl}_{10}$ excitonic peak.

In addition, under $\mathrm{UV}$ irradiation $(\mathrm{TAE})_{2}\left[\mathrm{~Pb}_{2} \mathrm{Cl}_{10}\right](\mathrm{Cl})_{2}$ single crystals show an impressive intense white light emission observable even with naked eyes at room temperature. Upon 3.81 $\mathrm{eV}$ laser (Figure 2(b)), the photoluminescence (PL) spectrum shows a broad band covering 
the entire of the visible range and resulting from the overlapof two bands located at $2.07 \mathrm{eV}$ and $2.83 \mathrm{eV}$, noted $\mathrm{S} 1$ and $\mathrm{S} 2$, respectively.

For a deep analysis of the PL spectrum and in order to investigate the contribution of the organic TAE cation and $\mathrm{Pb}_{2} \mathrm{Cl}_{10}$ inorganic anion in the emission process, we have studied under the same conditions the PL spectrum of the organic salt, which exhibits an intense and wide band at $3.07 \mathrm{eV}$. By comparison of both spectra, one can attribute the two components of the white light emission as follows: The S2 peak at 2.83 is unambiguously associated to the HOMO-LUMO electronic transitions within the organic cation. The $240 \mathrm{meV}$ red shift could be assigned to the interaction between organic and inorganic components in the $(\mathrm{TAE})_{2}\left[\mathrm{~Pb}_{2} \mathrm{Cl}_{10}\right](\mathrm{Cl})_{2}$ leading to tune the band structure and to modify the luminescence properties. $^{71}$

Whereas, the $\mathrm{S} 1$ peak at $2.07 \mathrm{eV}$ originates from excitonic levels of the $\mathrm{Pb}_{2} \mathrm{Cl}_{10}$ bioctahedra, and to boost this assumption, we have recorded the photoluminescence excitation (PLE) spectrum at $2.07 \mathrm{eV}$ (Figure 2(e)). The measurements reveal the presence of a sharp peak at $3.95 \mathrm{eV}(313 \mathrm{~nm})$, typically characteristic of the well-known Wannier-type excitons observed in similar compounds based on $\mathrm{PbCl}_{6}$ octahedra. ${ }^{57,66}$ On the other hand, the very large stokes shift with respect to excitons absorption $(1.7 \mathrm{eV})$ may be interpreted as a result of the strong interaction between the organic and inorganic ions. From an optoelectronic point of view, this material is then assimilated to the self-assembly of two luminescent organic and inorganic ionic entities, placed in very close positions ( 2 to $3 \AA$ ) and having almost equal HOMOLUMO gaps around (3.95 eV). Such characteristics have been observed in many metal halide hybrids and have been considered to favor strong interactions leading to the emission of broad bands of white light. ${ }^{38,53,61,72}$ It is well known that this type of interaction is characterized by a photoluminescence spectrum strongly dependent on the excitation wavelength. ${ }^{38,61,72}$ 
In this context, we carried out photoluminescence measurements under different excitations presented in the right side of Figure 2. For an excitation of $4.66 \mathrm{eV}$, energy above the organic and inorganic gap, the two entities are excited and their resonant interaction strongly enhances the intensities of both S1 and S2 peaks, giving rise to a single very wide band and a white light of impressive intensity. For an excitation of $3.81 \mathrm{eV}$, energy included in the organic and inorganic absorption bands tails, the two species are excited and we observe both S1 and S2 resolved peaks, with a lower intensity than the previous one. When exciting by energyof 3.3 $\mathrm{eV}$, only the organic cation is excited and the PL spectrum is reduced to the single band, as if the bioctahedra do not exist.
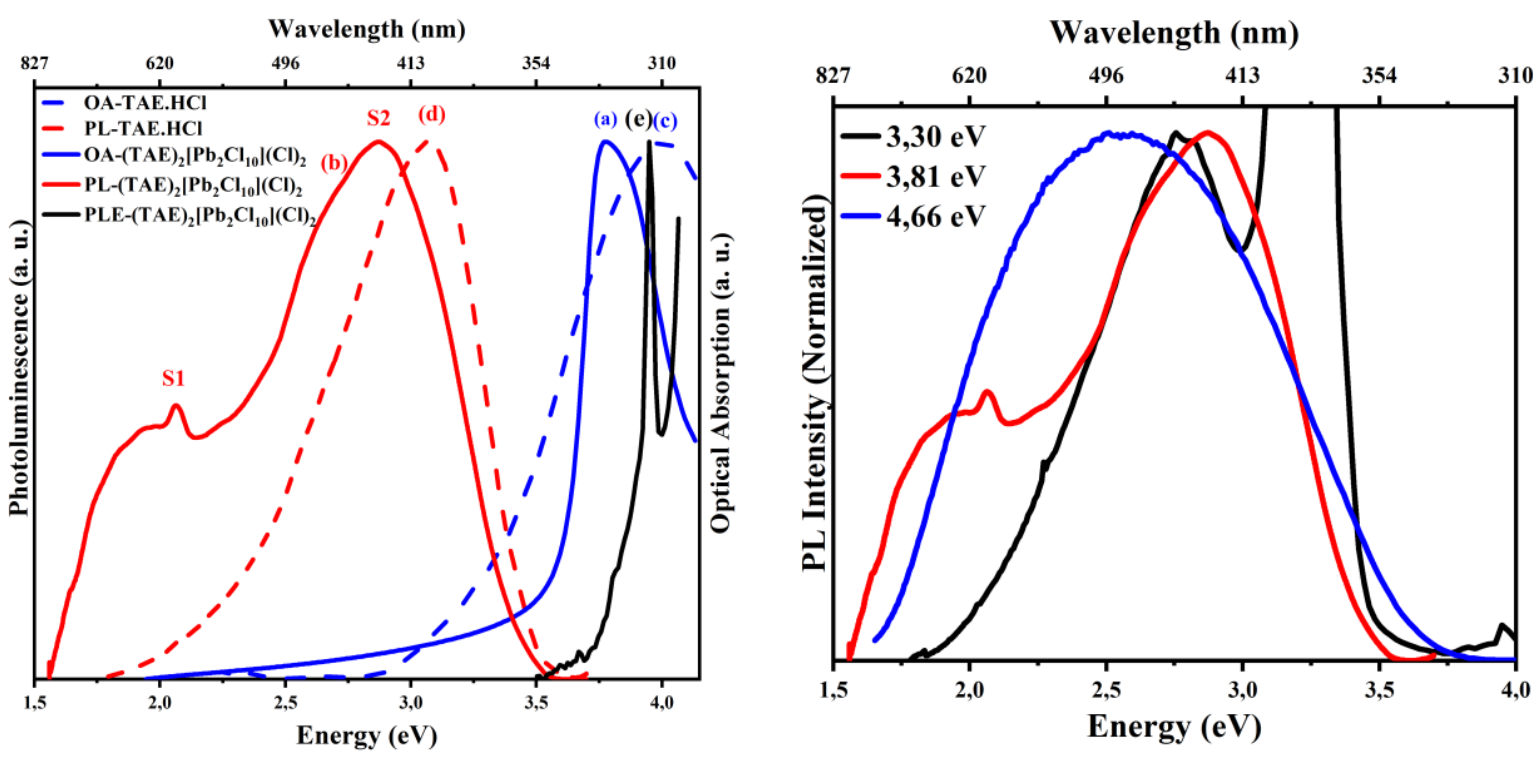

Figure2. (Left) $(\mathrm{a}, \mathrm{b})$ Optical absorption spectrum (solid blue line) and the PL emission spectrum (solid red line) of the OIH material (TAE) ${ }_{2}\left[\mathrm{~Pb}_{2} \mathrm{Cl}_{10}\right](\mathrm{Cl})_{2}$. (c,d) Optical absorption spectrum (dashed blue line) and the PL emission spectrum (dashed red line) of the ammonium

salt TAE.HCl. (e) PLE spectrum (solid black line) of the (TAE) $2\left[\mathrm{~Pb}_{2} \mathrm{Cl}_{10}\right](\mathrm{Cl})_{2}$ material. (Right) PL emission spectra of $(\mathrm{TAE})_{2}\left[\mathrm{~Pb}_{2} \mathrm{Cl}_{10}\right](\mathrm{Cl})_{2}$ excited with (black) $3.30 \mathrm{eV}$, (red) 3.81 White-Light Emission $\mathrm{eV}$ and (blue) $4.66 \mathrm{eV},(\mathrm{T}=300 \mathrm{~K})$.

As mentioned above, the studies conducted so far on hybrids based on lead halides have shown that the white light emission mechanisms as well as the profiles of the PL bands depend on many parameters, mainly, the optical activity of the organic cation, the distortion of the inorganic subnetwork and dimensionality. In order to better understand the white light 
emission mechanism in our material, we have carried out a comparative study of the photophysical characteristics of the materials studied so far. In table 1, we have gathered their main optical characteristics. An overview of these properties shows without ambiguity that for chlorinated and brominated compounds, the lowering in dimensionality is accompanied by a blue shift of the emission peak. Indeed, it was recently demonstrated that lowering the system dimensionality helps in the formation of exciton self-trapping at any exciton-phonon interaction strength, and leads to the observation of broad band luminescence with large stokes shifts. ${ }^{43}$ Furthermore, these studies have shown that the common characteristic to all these materials lies in the fact that the emission of broad bands involves the recombinations of self-trapped excitons, due to the high distortion of the $\mathrm{PbX}_{6}$ octahedra.

As we mentioned in the description of the structure, our material belonging to the lowdimensional OD HOIM family, does not escape the rule and exhibits a remarkle distortion, stronger than those reported in the literature. In order to probe the contribution of such selftrapped excitonic states in the emission mechanism, we carried out a study of the PL intensity as a function of the excitation power, which presents an excellent tool to confirm the self trapping excitons origin. ${ }^{40,44,46}$ As shown in Figure 4, the intensity of the white light emission excited at $4.66 \mathrm{eV}$ showed a linear dependence on the excitation power density up to 25 $\mathrm{MW} / \mathrm{cm}^{2}$, suggesting that the current WL emission originated from self-trapped excited states. Such a behavior is in good agreement with previous works, especially the results of Dohner et al. on (N-MEDA) $\mathrm{PbBr}_{4}{ }^{41}$ and (EDBE) $\mathrm{PbBr}_{4} .^{40} \mathrm{We}$ can then conclude, that in addition to the organic and inorganic free excitons involved in the mechanism described above, is added the contribution of the self-trapped excitons. This can explain the impressive intensity of the white light emission, as well as the remarkable width of the PL band. Indeed, in the comparative table, the most remarkable property we can notice in terms of properties structure correlation is the unprecedented width of the emission band of our compound (1.25 
$\mathrm{eV}$ ). To our knowledge, this value stand for the record of the broadening emission observed between overall the WL emitting $\mathrm{OIH}$ materials that did not exceed the value of $1 \mathrm{eV}$.

In order to better illustrate the interesting findings of our $0 \mathrm{D} \mathrm{OIH}$ material $(\mathrm{TAE})_{2}\left[\mathrm{~Pb}_{2} \mathrm{Cl}_{10}\right](\mathrm{Cl})_{2}$, the white light characteristics, namely the CIE coordinates, the (CCT) and the (CRI), are also presented for comparaison with those of other WL emitting HOI based materials in Table 1. In this study, the $(\mathrm{TAE})_{2}\left[\mathrm{~Pb}_{2} \mathrm{Cl}_{10}\right](\mathrm{Cl})_{2}$ excited with the $4.66 \mathrm{eV}$ laser exhibits CIE coordinates at $(0.30,0.33)$ very close to the reference coordinates $(0.33,0.33)$ defined in the CIE chart as the white point or equal energy point (Figure 3). Also, the broad band emission from this material exhibits a CCT of 6741 that affords "cold" white light. Most importantly, the value of the CRI is evaluated at 96 , which is the highest value revealed among the other WL emissions from other OIH materials ${ }^{67}$ (see Table 1) and exceeds even the high CRI indexes (>90) exhibited by some mixed-phosphor light sources. ${ }^{3,7}$ Generally, the desired indoor lighting applications typically require values of CRI above 80 and closest to 100 which is, by definition, the black body radiator CRI. ${ }^{73,74}$ Moreover, from the CRI values depicted in Table 1, we concluded that the highest values are those obtained from chlorided materials and this agree well with the hypothesis conceived by Dohner et al. that chloride substitution improves the material's properties (CRI). ${ }^{41}$ All of these characteristics clearly show the important originality of this new material, and can enable applications sought for many indoor lighting requiring inexpensive and large-area coatings.

Table1. Reported photophysical properties and white light characteristics in some $\mathrm{OIH}$ materials.

\begin{tabular}{|c|c|c|c|c|c|c|c|}
\hline \multirow[b]{2}{*}{ Compound } & \multicolumn{4}{|c|}{ Photophysical properties (eV) } & \multicolumn{3}{|c|}{ White light characteristics } \\
\hline & PL & Abs & $\begin{array}{l}\text { Stokes } \\
\text { Shifts }\end{array}$ & FWHM & $\begin{array}{l}\text { CIE } \\
(\mathbf{x}, \mathbf{y})\end{array}$ & $\begin{array}{c}\text { CCT } \\
\text { (K) }\end{array}$ & CRI \\
\hline $\mathrm{EDBE} \mathrm{PbBr}_{4}(2 \mathrm{D})^{40}$ & 2.16 & 3.34 & 1.18 & 0.8 & $0.39,0.42$ & 3990 & 84 \\
\hline$\left(\mathrm{C}_{6} \mathrm{H}_{14} \mathrm{NH}_{3}\right)_{2} \mathrm{PbBr}_{4}(2 \mathrm{D})^{42}$ & 2 & 3.19 & 1.2 & 0.66 & - & - & - \\
\hline $\mathrm{N}$ MEDA $\mathrm{PbBr}_{4}(2 \mathrm{D})^{41}$ & 2.22 & 3.13 & 0.91 & 0.9 & $0.36,0.41$ & 4669 & 82 \\
\hline $\mathrm{AEA} \mathrm{PbBr}_{4}(2 \mathrm{D})^{45}$ & 2 & 3.3 & 1.3 & - & $0.29,0.34$ & - & 87 \\
\hline $\mathrm{C}_{4} \mathrm{~N}_{2} \mathrm{H}_{14} \mathrm{PbBr}_{4}(1 \mathrm{D})^{46}$ & 2.61 & 3.3 & 0.69 & 0.9 & $0.21,0.28$ & - & 63 \\
\hline $\mathrm{C}_{4} \mathrm{~N}_{2} \mathrm{H}_{14} \mathrm{PbBr}_{4}(1 \mathrm{D})^{46}$ & 2.61 & 3.3 & 0.69 & 0.9 & $0.21,0.27$ & - & 66 \\
\hline
\end{tabular}




\begin{tabular}{|c|c|c|c|c|c|c|c|}
\hline $\mathrm{EDBE} \mathrm{PbCl}_{4}(2 \mathrm{D})^{40}$ & 2.3 & 3.53 & 1.23 & 0.95 & $0.33,0.39$ & 5509 & 81 \\
\hline $\mathrm{PEPC} \mathrm{PbCl}_{4}(2 \mathrm{D})^{47}$ & 2.1 & 3.64 & 1.54 & - & $0.37,0.42$ & 4426 & 84 \\
\hline$\left(\mathrm{C}_{4} \mathrm{H}_{9} \mathrm{NH}_{3}\right)_{2} \mathrm{PbCl}_{4}(2 \mathrm{D})^{65}$ & 2.28 & - & - & - & $0.37,0.40$ & 4423 & 86 \\
\hline$\left(2 \mathrm{meptH}_{2}\right) \mathrm{PbCl}_{4}(2 \mathrm{D})^{62}$ & 2.15 & 3.51 & 1.36 & 0.73 & $0.39,0.44$ & 3958 & 84 \\
\hline $\mathrm{C}_{6} \mathrm{H}_{12} \mathrm{~N}_{3} \mathrm{PbCl}_{4}(2 \mathrm{D})^{64}$ & 2.16 & 3.26 & 1.1 & 0.86 & $0.36,0.37$ & 4203 & 93 \\
\hline $\mathrm{AQ} \mathrm{PbCl}_{4}(1 \mathrm{D})^{57}$ & 2.3 & 3.22 & 0.92 & - & $0.29,0.43$ & - & - \\
\hline $\mathrm{C}_{4} \mathrm{~N}_{2} \mathrm{H}_{14} \mathrm{PbCl}_{4}(1 \mathrm{D})^{63}$ & 2.47 & 3.87 & 1.4 & 0.854 & $0.29,0.39$ & 3880 & - \\
\hline $\mathrm{C}_{4} \mathrm{~N}_{2} \mathrm{H}_{14} \mathrm{PbCl}_{4}(1 \mathrm{D})^{63}$ & 2.19 & 3.87 & 1.68 & 0.664 & $0.40,0.43$ & 3880 & - \\
\hline $\mathrm{C}_{5} \mathrm{H}_{14} \mathrm{~N}_{2} \mathrm{PbCl}_{4} \cdot \mathrm{H}_{2} \mathrm{O}(1 \mathrm{D})^{61}$ & 2 & - & - & - & $0.39,0.37$ & 3445 & 94 \\
\hline$(\mathrm{TAE})_{2}\left[\mathrm{~Pb}_{2} \mathrm{Cl}_{10}\right](\mathrm{Cl})_{2}(\mathrm{OD})$ & 2.51 & 3.77 & 1.26 & 1.25 & $0.30,0.33$ & 6741 & 96 \\
\hline
\end{tabular}
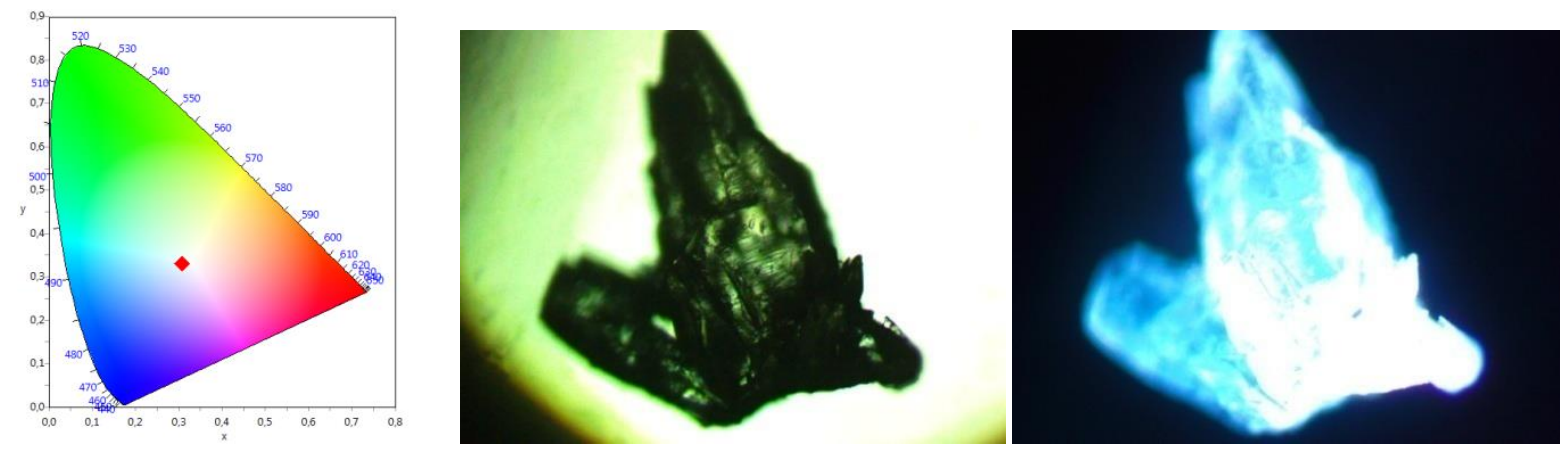

Figure3. (Left) CIE Chromaticity coordinates of (TAE $)_{2}\left[\mathrm{~Pb}_{2} \mathrm{Cl}_{10}\right](\mathrm{Cl})_{2}$ emission excited by $4.66 \mathrm{eV}$.(Right) Photographsshowing the samemicrocrystal before and during photoluminescence under $3.30 \mathrm{eV}$ irradiation $(\mathrm{T}=300 \mathrm{~K})$.
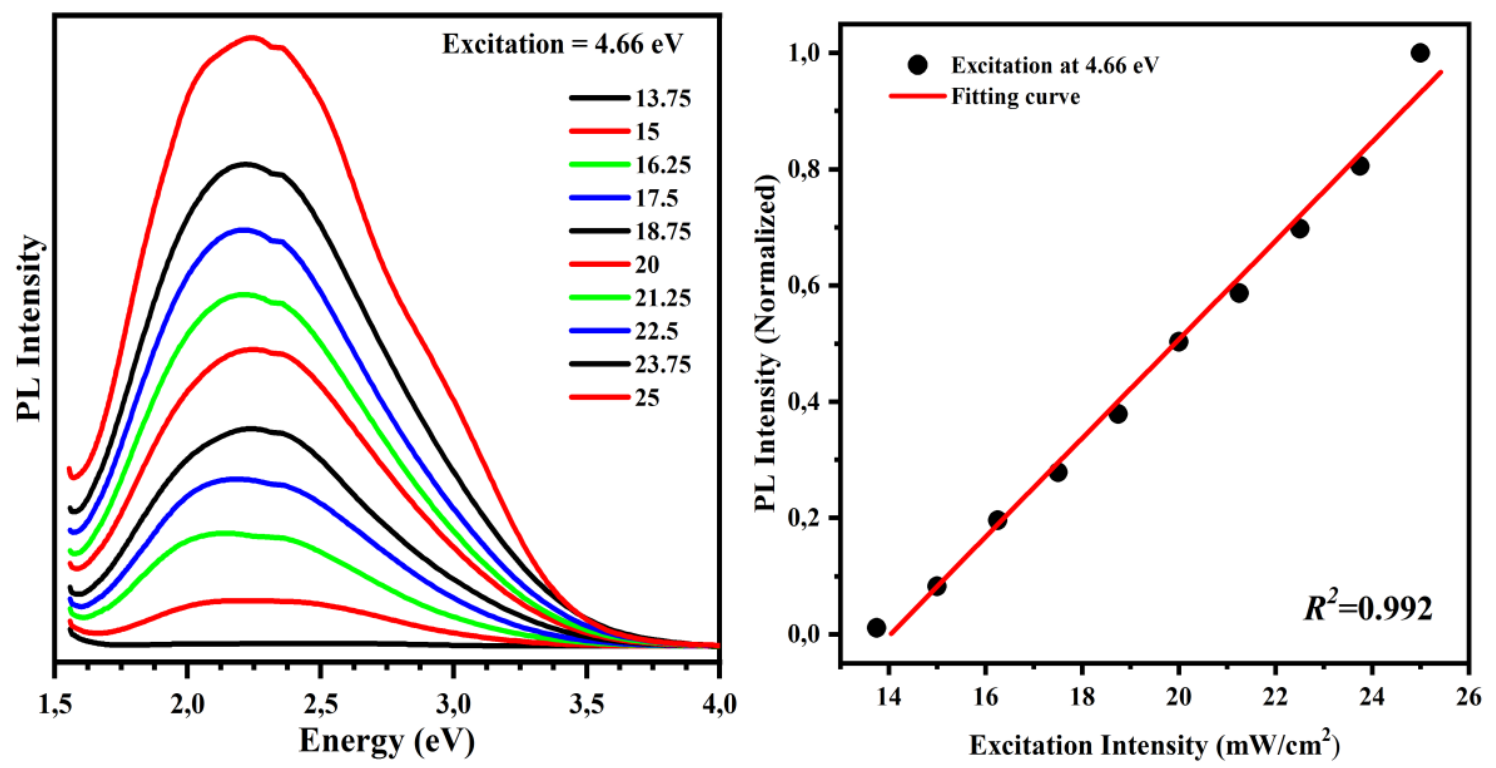

Figure 4. (Left) Variation of the emission spectra at $4.66 \mathrm{eV}$ with different excitation intensities (13.75-25 $\left.\mathrm{mW} / \mathrm{cm}^{2}\right)$. (Right) Linear dependence of emission intensity on excitation density and a linear fit, $(\mathrm{T}=300 \mathrm{~K})$. 


\section{Temperature Dependence of WL Emission}

To get further information about the stability of excitons, we measured the thermal dependence of the emission spectra of the $\mathrm{OIH}$ compound $(\mathrm{TAE})_{2}\left[\mathrm{~Pb}_{2} \mathrm{Cl}_{10}\right](\mathrm{Cl})_{2}$ in the temperature range $[10-300 \mathrm{~K}]$. As shown in Figure 5a, significant changes were observed on the behaviors of S1 and S2 PL lines. The integrated intensity of peak S1 continuously decreases as a function of temperature and shows an anomaly around $50 \mathrm{~K}$. We described the quenching of S1 excitonic PL emission as a function of temperature, as a consequence of the competition with a non-radiative channel which described by the Arrhenius-type law, ${ }^{75,76}$

$$
I_{P L}=\frac{I_{0}}{1+\operatorname{aexp}\left(\frac{-E a}{k_{B} T}\right)}
$$

where $I_{0}$ is the low-temperature PL intensity, $\mathrm{k}_{\mathrm{B}}$ is the Boltzmann constant, $a$ is the ratio between the radiative and the nonradiative decay rates, and $E_{a}$ is the activation energy. The best fit gives $I_{0}=2.7 \times 10^{4} \pm 480$ (a.u), $a=25 \pm 7$, and $E_{a}=5 \pm 0.5 \mathrm{meV}$. This activation energy presents a good agreement with those measured in similar 2D OIHP such as $\left(\mathrm{C}_{6} \mathrm{H}_{11} \mathrm{NH}_{3}\right)_{2} \mathrm{PbBr}_{4}{ }^{42}$ and $\left(\mathrm{C}_{6} \mathrm{H}_{5} \mathrm{C}_{2} \mathrm{H}_{4} \mathrm{NH}_{3}\right)_{2} \mathrm{PbI}_{4}{ }^{77}$ On the other hand, S2 PL peak intensity shows three different behaviors as a function of temperature (Figure 5b): first, it decreases until reaching $50 \mathrm{~K}$ (region I), then increases between 50 and $180 \mathrm{~K}$ (region II) and finally quenches at higher temperature (region III). More importantly, at room temperature (curve b in Figure 5), the emission spectrum of (TAE $)_{2}\left[\mathrm{~Pb}_{2} \mathrm{Cl}_{10}\right](\mathrm{Cl})_{2}$ was dominated by $\mathrm{S} 2 \mathrm{PL}$ band and on cooling, three different behaviors were observed. Indeed, as displayed in the inset of Figure $5 b$, in the temperature range (I), S1 peak is dominant and the ratio between S1 and S2 increases, then it suddenly decreases in region II, and below $180 \mathrm{~K}$ the S1 PL band becomes dominant, and the ratio between S1 and S2 PL intensities stabilizes in region III above $180 \mathrm{~K}$. Such behavior can be explained by two ways. First, it is well known that excitons stability is 
much higher at low temperature. ${ }^{78}$ Therefore; the intensity of $\mathrm{S} 1$ excitonic peak enhances by lowering the temperature and becomes much sharper. Second, the presence of a singularity around $50 \mathrm{~K}$ on the thermal behavior of $\mathrm{S} 1$ could be the result of structural distortions often observed at low temperature in $\mathrm{OIH}$ materials. ${ }^{40-42}$ On the other hand, the evidence of three different temperature ranges on the thermal behavior of the integrated intensity of S2 PL band further strengthens the hypothesis of the presence of critical structural changes especially around 50 and $180 \mathrm{~K}$. Moreover, the abnormal increase of the intensity of S2 PL peak between 50 and $180 \mathrm{~K}$ is accompanied by the decreases of S1 PL intensity, which suggests the presence of a strong competition in the recombination processes of S1 and S2 PL bands, which can be activated by the presence of structural phase transitions in this temperature range. ${ }^{79}$ Similar behavior was also found in the temperature dependence of the full width at half maximum (FWHM) of S1 and S2 PL peaks. Indeed, the FWHM of S1 excitonic peak slightly decreases in region I, and then continuously increases as a function of temperature (Figure 5c). Assuming linear electron-phonon coupling and harmonic lattice vibrations, the temperature dependence of the FWHM of S1 PL peak allows estimating the vibrational modes effective frequency coupled to the electronic transition using the following model: ${ }^{80}$

$$
\Gamma(T)=\Gamma_{0}+\Gamma_{\mathrm{LO}}\left(\mathrm{e}^{\frac{\mathrm{E}_{\mathrm{LO}}}{\mathrm{k}_{\mathrm{B}} \mathrm{T}}}-1\right)^{-1}+\Gamma_{\mathrm{inh}} \mathrm{e}^{\frac{-\mathrm{E}_{\mathrm{b}}}{\mathrm{k}_{\mathrm{B}} \mathrm{T}}}
$$

where, $\Gamma_{0}$ is the emission FWHM at $0 \mathrm{~K}, \mathrm{E}_{\mathrm{LO}}$ is the energy of the longitudinal optical phonon mode coupled to the electronic transition, $\mathrm{E}_{\mathrm{b}}$ represents the average binding energy of emissive defect states, and the constants $\Gamma_{\mathrm{LO}}$ and $\Gamma_{\text {inh }}$ give the relative contributions of electron-phonon coupling and inhomogeneous broadening to the emission line width. The best fit of the data (Figure 5c) gives $\mathrm{E}_{\mathrm{LO}}=6 \pm 1 \mathrm{meV}, \mathrm{E}_{\mathrm{b}}=12 \pm 3 \mathrm{meV}, \Gamma_{0}=193 \pm 8 \mathrm{meV}$, $\Gamma_{\mathrm{LO}}=170 \pm 6 \mathrm{meV}$ and $\Gamma_{\mathrm{inh}}=93 \pm 7 \mathrm{meV}$. 
Here, some concluding remarks can be drawn. (i) First, these fitting values are in agreement with those obtained from previous broad emitting 2D perovskites. ${ }^{40,49,60}$ Although the value of $\Gamma_{\mathrm{LO}}(170 \pm 6 \mathrm{meV})$ is slightly larger than the ones available in the literature of broad emitting lead bromide perovskites: $(130 \pm 7 \mathrm{meV})^{40}$ and $(131 \pm 7 \mathrm{meV}) ;^{60}$ however all these values remain considerably larger (up to more than threefold) than those of WL emitting lead chloride based perovskites $(49 \pm 3 \mathrm{meV}) .{ }^{49}$ The present tendency clearly reveals the existence of a strong exciton-phonon coupling in (TAE) $)_{2}\left[\mathrm{~Pb}_{2} \mathrm{Cl}_{10}\right](\mathrm{Cl})_{2}$ material. (ii) The LO phonon energy $\left(E_{\mathrm{LO}}=6 \pm 1 \mathrm{meV}\right.$ ) obtained from this fitting of Eq. (2), agrees well with the activation energy $\left(E_{a}=6 \pm 1 \mathrm{meV}\right)$ deduced from the Arrhenius fitting of the integrated intensity of S1 peak. In addition, this LO phonon energy along with the $\mathrm{E}_{\mathrm{b}}$ energy can be coincided with the frequencies of $67 \mathrm{~cm}^{-1}(8.3 \mathrm{meV})$ and $90 \mathrm{~cm}^{-1}(11.2 \mathrm{meV})$, evidenced by Raman spectroscopy (Figure S5) and so well align well within the range of $\mathrm{PbCl}$ stretching frequencies. In the same context, we observed an intense Raman scattering of our material at room temperature, further confirming the existence of an electron-phonon coupling in a strongly deformable lattice. (iii) We can then attribute the exciton self-trapping process in the current material to originate primarily from the inorganic lattice like concluded by $\mathrm{Hu}$ et al. for (NMEDA) $\left[\mathrm{PbBr}_{4}\right]$ material. ${ }^{43}$

On the other hand, the temperature dependence of the FWHM of S2 peak shows three different regimes for each temperature range which suggests, once again, the possible presence of structural changes as a function of temperature. Concerning the thermal behavior of S1 and S2 PL position, they keep almost the same position as a function of temperature, with the presence of singularity around $180 \mathrm{~K}$, for the position of S2 peak (Figure 5d). 
(a)

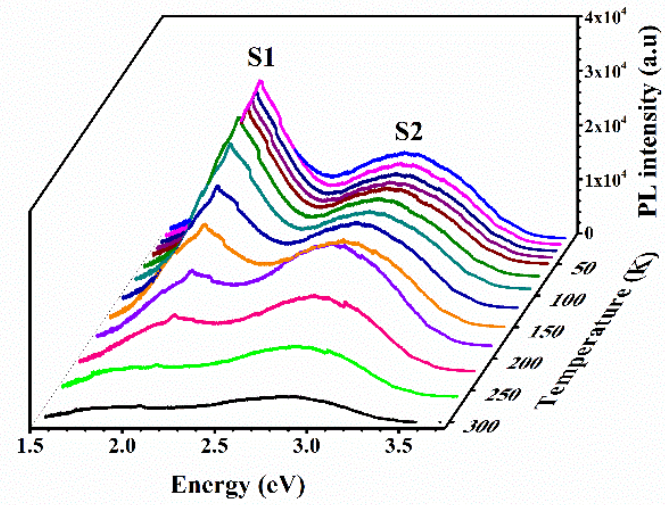

(c)

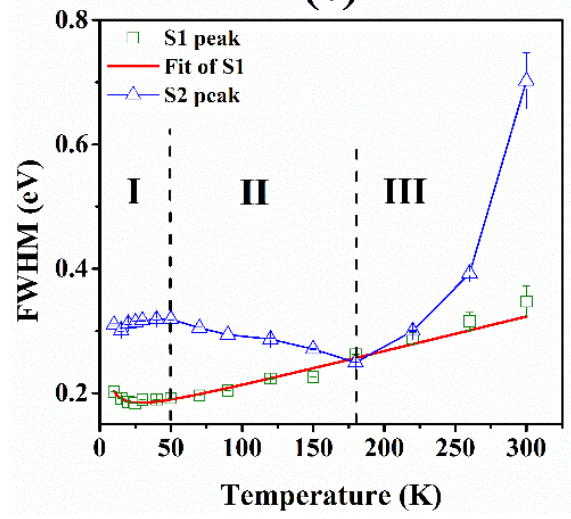

(b)

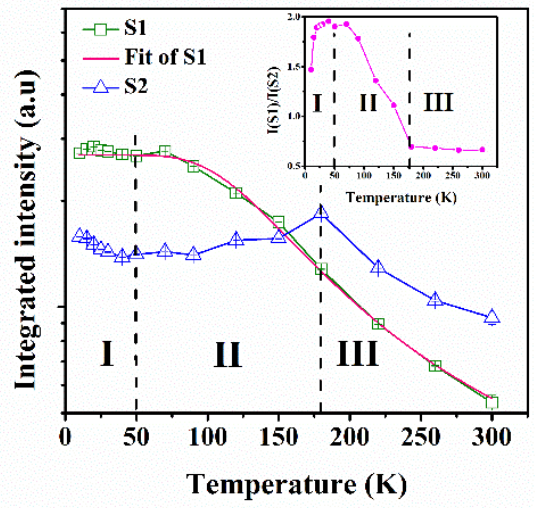

(d)

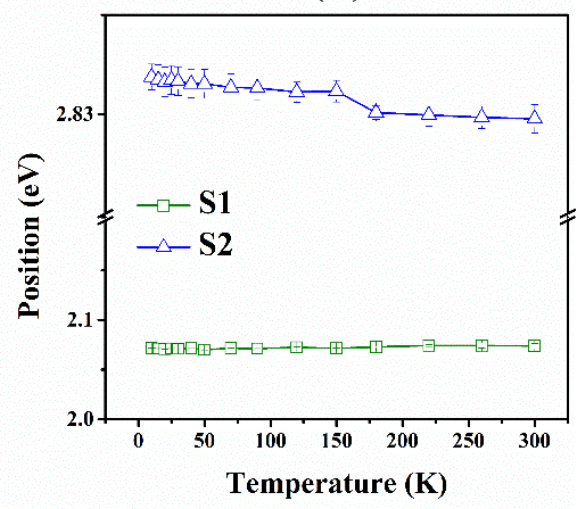

Figure5. (a) 3D plot of the temperature dependence of the PL spectra of $(\mathrm{TAE})_{2}\left[\mathrm{~Pb}_{2} \mathrm{Cl}_{10}\right](\mathrm{Cl})_{2}$ single crystals, in 10-300 $\mathrm{K}$ temperature range, under $3.816 \mathrm{eV}$ excitation. Plot of temperature dependence of (b) the integrated intensity, (c) FWHM, and (d) the peak position of both S1 and S2 PL peaks. Inset of Figure 5b shows the ratio between intensities of S1 and S2 as a function of temperature.

Figure 6a, shows the temperature dependence of the PL spectra of the ammonium salt TAE.HCl. Here as well, the study of the thermal dependence of the integrated intensity, FWHM and the position of the PL peak (Figures $6 \mathrm{~b}, 6 \mathrm{c}$ and $6 \mathrm{~d}$, respectively) shows the existence of three different temperature regimes (noted I, II, and III in Figure 6) which appear almost in the same temperature ranges as those observed in the $\mathrm{OIH}$ material $(\mathrm{TAE})_{2}\left[\mathrm{~Pb}_{2} \mathrm{Cl}_{10}\right](\mathrm{Cl})_{2}$. Indeed, the intensity of the maximum emission first decreases until $60 \mathrm{~K}$ (region I), then increases between 60 and $200 \mathrm{~K}$ (region II), and finally quenches at higher temperature (Figure 6b). Moreover, the FWHM of the emission band increases in region I, then decreases in region II and finally increases at higher temperature in region III. 
More importantly, the maximum emission of TAE. $\mathrm{HCl}$ ammonium salt strongly blue-shifts between 100 and $130 \mathrm{~K}$.

(a)

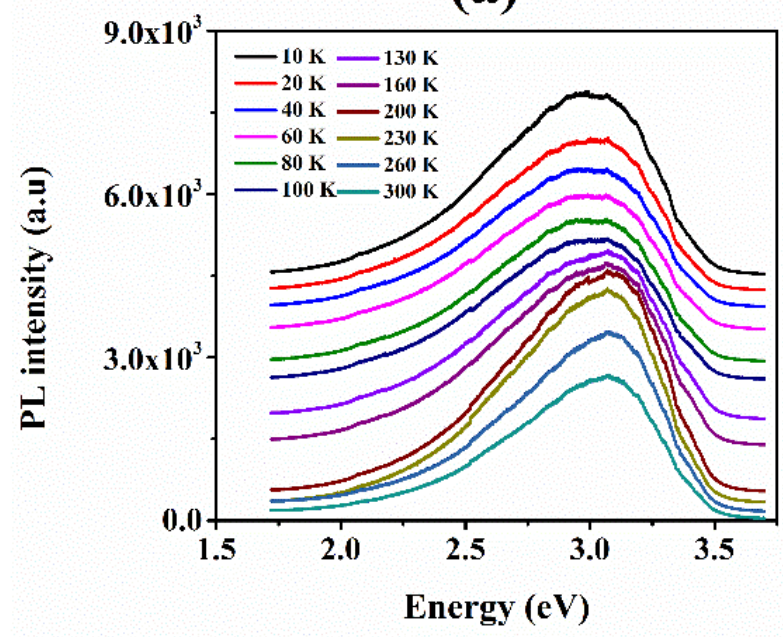

(c)

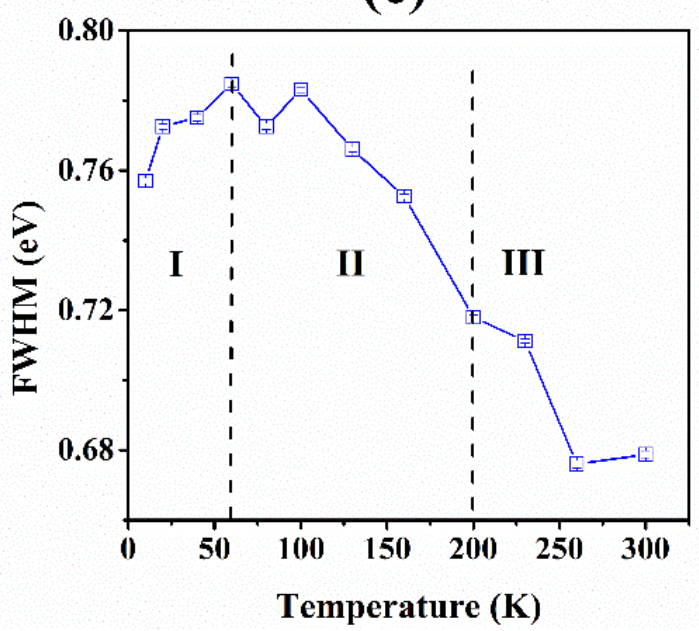

(b)

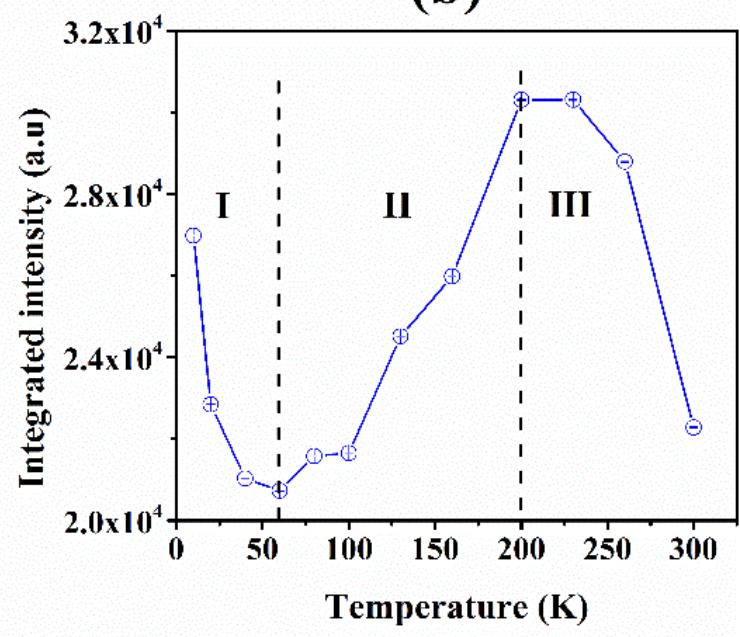

(d)

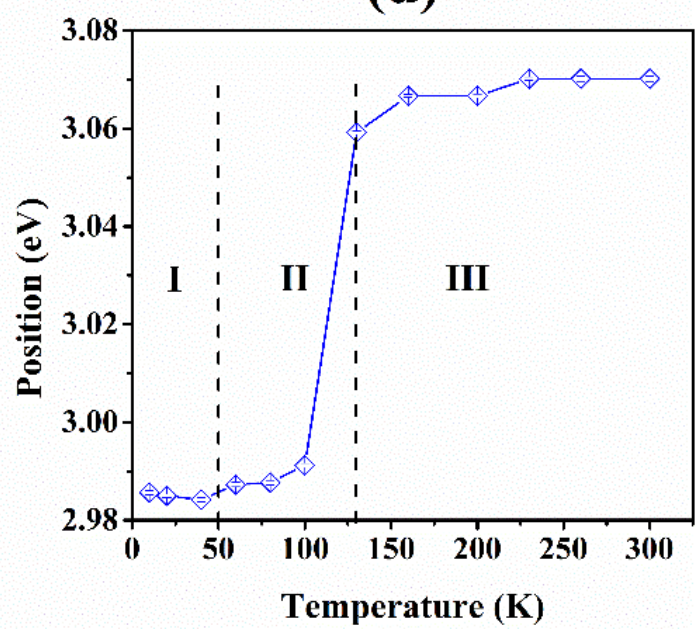

Figure 6. (a) Temperature dependence of the PL spectra of TAE.HCl ammonium salt. Plot of the temperature dependence of (b) the integrated intensity (c) the FWHM and (d) the position of the PL peak.

\section{Conclusion}

In summary, we have synthesized a novel low-dimensional lead chloride-based OIH material by slow solvent evaporation at room temperature. The crystal structure done using single crystal X-ray diffraction shows a $0 \mathrm{D}$ structure formed by discrete $\left[\mathrm{Pb}_{2} \mathrm{Cl}_{10}\right]^{6-}$ entities and two $[\mathrm{TAE}]^{4+}$ organic cations located in general positions and two $\mathrm{Cl}^{-}$chlorine ions. The 
investigations of the photo-physical properties revealed a sharp excitonic absorption and a very broadband WL emission, even at room temperature, consisting of two PL bands (S1 and S2) located respectively at 2.07 and $2.83 \mathrm{eV}$, attributed respectively, to free excitons confined into the inorganic bi-octahedra $\mathrm{Pb}_{2} \mathrm{Cl}_{10}$ and in the organic salts, respectively. This material excited by $4.66 \mathrm{eV}$ irradiation, exhibited a white light emission with record of the emission broadening with $1.25 \mathrm{eV}(247 \mathrm{~nm})$ as FWHM and offered the highest CRI value of 96. This is the effect of the supplementary light emissions from self trapped excitons generated within the highly distorted $\mathrm{Pb}_{2} \mathrm{Cl}_{10}$ bi-octahedras. We can state now that our material exhibits a very particular case of HOIM by showing a competition of three emission mechanisms, organic and inorganic free excitons and self trapped excitons. From the study of the temperature dependence of PL spectra of this OIH material, we deduced an exciton activation energy $E_{a}=6 \mathrm{meV}$ and detected the presence of singularities around 50 and $180 \mathrm{~K}$ on the behaviors of the thermal dependence integrated intensity, the FWHM, and the position of the PL peaks. These singularities were also tracked from the study of the thermal dependences of the PL spectra of the associated ammonium salt, and are attributed to structural phase transitions, often observed in $\mathrm{OIH}$ perovskites materials.

Considering the low cost character of the present new WL material, its room-temperature facile synthesis and excellent optical properties, this new perovskite phosphor which enriches the restricted list of WL OIH materials, represents a highly promising alternative to replace conventional inorganic rare-earth-based phosphors and quantum dot-based phosphors that currently dominate the field of optically pumped WLEDs.

Supporting Information: Crystallographic data, relevant structural parameters, crystal and molecular structures descriptions and Raman spectrum. 


\section{REFERENCES}

[1] U.S. Department of Energy and Optoelectronics Industry Development Association. The Promise of Solid State Lighting for General Illumination; Optoelectronics Industry Development Association: Washington DC. 2002.

[2] Wang, M. S.; Guo, S. P.; Li, Y.; Cai, L. Z.; Zou, J. P.; Xu, G.; Zhou, W. W.; Zheng, F. K.; Guo, G. C. Direct White-Light-Emitting Metal-Organic Framework with Tunable Yellow-toWhite Photoluminescence by Variation of Excitation Light J. Am. Chem. Soc. 2009, 131, 13572-13573.

[3] Kitai, A. Luminescent Materials and Applications; John Wiley \& Sons 2008.

[4] Ye, S.; Xiao, F.; Pan, Y. X.; Ma, Y. Y.; Zhang, Q. Y. Phosphors in phosphor-converted white light-emitting diodes: Recent advances in materials, techniques and properties Materials Science and Engineering $R$ 2010,71, 1-34.

[5] Kamtekar, K. T.; Monkman, A. P.; Bryce, M. R. Recent Advances in White Organic Light-Emitting Materials and Devices (WOLEDs) Adv. Mater. 2010, 22, 572-582.

[6] Colella, S.; Mazzeo, M.; Rizzo, A.; Gigli, G.; Listorti, A. The Bright Side of Perovskites J. Phys. Chem. Lett. 2016, 7, 4322-4334.

[7] Saparov, B.; Mitzi, D. B. Organic-Inorganic Perovskites: Structural Versatility for Functional Materials Design Chem. Rev. 2016, 116, 4558-4596.

[8] Stoumpos, C. C.; Kanatzidis, M. G. Halide Perovskites: Poor Man's High-Performance Semiconductors Adv. Mater. 2016, 28, 5778-5793.

[9] Zhou, C.; Lin, H.; Lee, S.; Chaaban, M.; Ma, B. Organic-inorganic metal halide hybrids beyond perovskites Materials Research Letters 2018, 6, 10, 552-569.

[10] Manser, J. S.; Christians, J. A.; Kamat, P. V. Intriguing Optoelectronic Properties of Metal Halide Perovskites Chem. Rev. 2016, 116, 12956-13008.

[11] Stoumpos, C. C.; Kanatzidis, M. G. The Renaissance of Halide Perovskites and Their Evolution as Emerging Semiconductors Acc. Chem. Res. 2015, 48, 2791-2802.

[12] Chondroudis, K.; Mitzi, D. B. Electroluminescence from an Organic-Inorganic Perovskite Incorporating a Quaterthiophene Dye with in Lead Halide Perovskite Layers Chem. Mater. 1999, 11, 3028-3030.

[13] Koutselas, I.; Bampoulis, P.; Maratou, E.; Evagelinou,T.; Pagona, G. ; Papavassiliou, G. C. Some Unconventional Organic-Inorganic Hybrid Low-Dimensional Semiconductors and Related Light-Emitting Devices J. Phys. Chem. C 2011, 115, 8475-8483.

[14] Tan, Z. K.; Moghaddam, R. S.; Lai, M. L.; Docampo, P.; Higler, R.; Deschler, F.; Price, M.; Sadhanala, A.; Pazos, L. M.; Credgington, D.; Hanusch, F.; Bein, T.; Snaith,H. J.; Friend, R. H. Bright light-emitting diodes based on organometal halide perovskite Nature Nanotechnology 2014, 9(9), 1-6.

[15] Yuan, M.; Quan, L. N.; Comin, R.; Walters, G.; Sabatini, R.; Voznyy, O.; Hoogland, S.; Zhao, Y.; Beauregard, E. M.; Kanjanaboos, P.; Lu, Z.; Kim, D. H.; Sargent, E. H. Perovskite energy funnels for efficient light-emitting diodes Nature Nanotechnology 2016, 11, 872-879.

[16] Mitzi, D. B.; Chondroudis, K. ; Kagan, C. R. Organic-inorganic electronics IBM J. RES. \& DEV. 2001, 45, 1,29-45. 
[17] Kagan, C. R.; Mitzi, D. B.; Dimitrakopoulos, C. D. Organic-Inorganic Hybrid Materials as Semiconducting Channels in Thin-Film Field-Effect Transistors Science 1999,286 (5441), 945-947.

[18] Mitzi, D. B.; Kosbar, L. L.; Murray, C. E.; Copel,M.; Afzali, A. High-mobility ultra thin semiconducting films prepared by spin coating Nature 2004, 428, 299-303.

[19]Mitzi, D. B. Solution-processed inorganic semiconductors J. Mater. Chem. 2004, 14, $2355-2365$.

[20] Wang, L.; Yoon, M. H.; Lu, G.; Yang, Y.; Facchetti, A.; Marks, T. J. High-performance transparent inorganic-organic hybrid thin-filmn-type transistors Nature Materials 2006, 5, 893-900.

[21] Chin, X. Y.; Cortecchia, D.; Yin, J.; Bruno, A.; Soci, C. Lead iodide perovskite lightemitting field-effect transistor Nat.Commun 2015,6, 7383, 1-9.

[22] Kim, H. S.; Lee, C. R.; Im, J. H.; Lee, K. B.; Moehl, T.; Marchioro, A.; Moon, S. J.; Baker, R. H.; Yum, J. H.; Moser, J. E.; Grätzel, M.; Park, N. G. Lead Iodide Perovskite Sensitized All-Solid-State Submicron Thin Film Mesoscopic Solar Cell with Efficiency Exceeding 9\% Sci. Rep. 2012, 2, 591, 1-7.

[23] Etgar, L.; Gao, P.; Xue, Z.; Peng, Q.; Chandiran, A. K.; Liu, B.; Nazeeruddin, M. K.; Grätzel, M. Mesoscopic $\mathrm{CH}_{3} \mathrm{NH}_{3} \mathrm{PbI}_{3} / \mathrm{TiO}_{2}$ Heterojunction Solar Cells J. Am. Chem. Soc. 2012, 134, 17396-17399.

[24] Burschka, J.; Pellet, N.; Moon, S. J.; Baker, R. H.; Gao, P.; Nazeeruddin, M. K.; Grätzel, M. Sequential deposition as a route to high-performance perovskite-sensitized solar cells Nature 2013, 499, 316-320.

[25] Heo, J. H.; Im, S. H.; Noh, J. H.; Mandal,T. N.; Lim, C. S.; Chang, J. A.; Lee, Y. H.; Kim, H. J.; Sarkar, A.; Nazeeruddin, M. K.; Grätzel, M.; Seok, S. I. Efficient inorganicorganic hybrid heterojunction solar cells containing perovskite compound and polymeric hole conductors Nature Photonics 2013, 80, 1-6.

[26] Jeon, N. J.; Lee, J.; Noh, J. H.; Nazeeruddin, M. K.; Grätzel, M.; Seok, S. I. Efficient Inorganic-Organic Hybrid Perovskite Solar Cells Based on Pyrene Arylamine Derivatives as Hole-Transporting Materials J. Am. Chem. Soc. 2013, 135, 19087-19090.

[27] Hao, F.; Stoumpos, C. C.; Cao, D. H.; Changand, R. P. H.; Kanatzidis, M. G. Lead-free solid-state organic-inorganic halide perovskite solar cells Nature Photonics 2014,82,1-6.

[28] Green, M. A.; Baillie, A. H.; Snaith, H. J. The emergence of perovskite solar cells Nature Photonics 2014, 8, 506-514.

[29] Yang, M.; Zhang, T.; Schulz, P.; Li, Z.; Li, G.; Kim, D. H.; Guo, N.; Berry, J. J.; Zhu, K.; Zhao, Y. Facile fabrication of large-grain $\mathrm{CH}_{3} \mathrm{NH}_{3} \mathrm{PbI}_{3-\mathrm{x}} \mathrm{Br}_{\mathrm{x}}$ films for high-efficiency solar cells via $\mathrm{CH}_{3} \mathrm{NH}_{3} \mathrm{Br}^{-}$selective Ostwald ripening Nat. Commun. 2016, 7, 12305, 1-9.

[30] McMeekin, D. P.; Sadoughi, G.; Rehman, W.; Eperon, G. E.; Saliba, M.; Hörantner, M. T.; Haghighirad, A.; Sakai, N.; Korte, L.; Rech, B.; Johnston, M. B.; Herz, L. M.; Snaith, H. J. A mixed-cation lead mixed-halide perovskite absorber for tandem solar cells Science 2016, $351,6269,151-155$.

[31] Yang, W. S.; Park, B. W.; Jung, E. H.; Jeon, N. J.; Kim, Y. C.; Lee, D. U.; Shin, S. S.; Seo, J.; Kim, E. K.; Noh, J. H.; Seok, S. I. Iodide management informamidinium-lead-halidebased perovskite layers for efficient solar cells Science 2017, 356, 6345, 1376-1379. 
[32] Bisquert, J. The Swift Surge of Perovskite Photovoltaics J. Phys. Chem. Lett. 2013, 4, 2597-2598.

[33] Even, J.; Pedesseau, L.; Jancu, J. M.; Katan, C. Importance of Spin-Orbit Coupling in Hybrid Organic/Inorganic Perovskites for Photovoltaic Applications J. Phys. Chem. Lett. 2013, 4, 2999-3005.

[34] Mosconi, E.; Amat, A.; Nazeeruddin, M. K.; Grätzel, M.; De Angelis, F. First-Principles Modeling of Mixed Halide Organometal Perovskites for Photovoltaic Applications J. Phys. Chem. C 2013, 117, 13902-13913.

[35] Kamat, P. V. Organometal Halide Perovskites for Transformative Photovoltaics J. Am. Chem. Soc. 2014, 136, 3713-3714.

[36] Escrig, L. G.; Sempere, A. M.; Sessolo, M.; Bolink, H. J. Mixed Iodide-Bromide Methylammonium Lead Perovskite-based Diodes for Light Emission and Photovoltaics $J$. Phys. Chem. Lett. 2015, 6, 3743-3748.

[37] Bruno, A.; Cortecchia, D.; Chin, X. Y.; Fu, K.; Boix, P. P.; Mhaisalkar, S.; Soci, C. Temperature and Electrical Poling Effects on Ionic Motionin MAPbI ${ }_{3}$ Photovoltaic Cells $A d v$. Energy Mater. 2017, 1700265, 1-9.

[38] Samet, A.; Pillet, S.; Abid, Y. Sensitizer-free photon up conversion in (HQ) ${ }_{2} \mathrm{ZnCl}_{4}$ and $\mathrm{HQCl}$ crystals: systems involving resonant energy transfer and triplet-triplet annihilation Phys. Chem. Chem. Phys. 2019, DOI: 10.1039/c9cp04435c.

[39] Wang, M. S.; Guo, G. C. Inorganic-organic hybrid white light phosphors Chem. Commun 2016, 52, 13194-13204.

[40] Dohner, E. R.; Jaffe, A.; Bradshaw, L. R.; Karunadasa, H. I. Intrinsic White-Light Emission from Layered Hybrid Perovskites J. Am. Chem. Soc. 2014, 136, 13154-13157.

[41] Dohner, E. R.; Hoke, E. T.; Karunadasa, H. I. Self-Assembly of Broadband White-Light Emitters J. Am. Chem. Soc. 2014, 136, 1718-1721.

[42] Yangui, A.; Garrot, D.; Lauret, J. S.; Lusson, A.; Bouchez, G.; Deleporte, E.; Pillet, S.; Bendeif, E. E.; Castro, M.; Triki, S.; Abid, Y.; Boukheddaden, K. Optical Investigation of Broadband White-Light Emission in Self-Assembled Organic - Inorganic Perovskite $\left(\mathrm{C}_{6} \mathrm{H}_{11} \mathrm{NH}_{3}\right)_{2} \mathrm{PbBr}_{4}$ J. Phys. Chem. C 2015, 119, 23638-23647.

[43] Hu, T.; Smith, M. D.; Dohner, E. R.; Sher, M. J.; Wu, X.; Trinh, M. T.; Fisher, A.; Corbett, J.; Zhu, X. Y.; Karunadasa, H. I.; Lindenberg, A. M. Mechanism for Broadband White-Light Emission from Two-Dimensional (110) Hybrid Perovskites J. Phys. Chem. Lett. 2016, 7, 2258-2263.

[44] Teunis, M. B.; Lawrence, K. N.; Dutta, P.; Siegela, A. P.; Sardar, R. Pure white-light emitting ultrasmall organic-inorganic hybrid perovskite nanoclusters Nanoscale 2016, 8, 17433-17439.

[45] Smith, M. D.; Jaffe, A.; Dohner, E. R.; Lindenberg, A. M.; Karunadasa, H. I. Structural origins of broadband emission from layered $\mathrm{Pb}-\mathrm{Br}$ hybrid perovskites Chem. Sci. 2017, 8, 4497-4504.

[46] Yuan, Z.; Zhou, C.; Tian, Y.; Shu, Y.; Messier, J.; Wang, J. C.; van de Burgt, L. J.; Kountouriotis, K.; Xin, Y.; Holt, E.; Schanze, K.; Clark, R.; Siegrist, T.; Ma, B. Onedimensional organic lead halide perovskites with efficient bluish white-light emission Nat. Commun. 2017, 8, 14051, 1-7. 
[47] Thirumal, K.; Chong, W. K.; Xie, W.; Ganguly, R.; Muduli, S. K.; Sherburne, M.; Asta, M.; Mhaisalkar, S.; Sum, T. C.; Soo, H. S.; Mathews, N. Morphology-Independent Stable White-Light Emission from Self-Assembled Two-Dimensional Perovskites Driven by Strong Exciton-Phonon Coupling to the Organic Framework Chem. Mater. 2017, 29, 3947-3953.

[48] Zhou, C.; Tian, Y.; Yuan, Z.; Lin, H.; Chen, B.; Clark, R.; Dilbeck, T.; Zhou, Y.; Hurley, J.; Neu, J.; Besara, T.; Siegrist, T.; Djurovich, P.; Ma, B. Highly Efficient Broadband Yellow Phosphor Based on Zero-Dimensional Tin Mixed-Halide Perovskite ACS Appl. Mater. Interfaces 2017, 9, 44579-44583.

[49] Zhuang, Z.; Peng, C.; Zhang, G.; Yang, H.; Yin, J.; Fei, H. Intrinsic Broadband WhiteLight Emission from Ultrastable, Cationic Lead Halide Layered Materials Angew. Chem. Int. Ed. 2017, 56, 14411-14416.

[50] Cortecchia, D.; Neutzner, S.; Kandada, A. R. S.; Mosconi, E.; Meggiolaro, D.; De Angelis, F.; Soci, C.; Petrozza, A. Broadband Emission in Two-Dimensional Hybrid Perovskites: The Role of Structural Deformation J. Am. Chem. Soc.2017, 139, 39-42.

[51] Dammak, T.; Abid, Y. Quasi-white light emission involving Forster resonance energy transfer in a new organic inorganic tin chloride based material (AMPS) [ $\left.\mathrm{SnCl}_{6}\right] \mathrm{H}_{2} \mathrm{O}$ Optical Materials 2017, 66, 302-307.

[52] Mao, L.; Wu, Y.; Stoumpos, C. C.; Wasielewski, M. R.; Kanatzidis, M. G. White-Light Emission and Structural Distortion in New Corrugated Two-Dimensional Lead Bromide Perovskites J. Am. Chem. Soc. 2017, 139, 5210-5215.

[53] Mao, L.; Wu, Y.; Stoumpos, C. C. ; Traore, B.; Katan, C.; Even, J.; Wasielewski, M. R.; Kanatzidis, M. G. Tunable White-Light Emission in Single-Cation-Templated Three-Layered 2D Perovskites $\left(\mathrm{CH}_{3} \mathrm{CH}_{2} \mathrm{NH}_{3}\right)_{4} \mathrm{~Pb}_{3} \mathrm{Br}_{10-\mathrm{x}} \mathrm{Cl}_{\mathrm{x}} J$. Am. Chem. Soc. 2017, 139, 11956-11963.

[54] Neogi, I.; Bruno, A.; Bahulayan, D.; Goh, T. W.; Ghosh, B.; Ganguly, R.; Cortecchia, D.; Sum, T. C.; Soci, C.; Mathews, N.; Mhaisalkar, S. G. Broadband-Emitting 2D Hybrid Organic-Inorganic Perovskite Based on Cyclohexane-bis(methylamonium) Cation ChemSusChem 2017, 10, 3765-3772.

[55] Smith, M. D.; Watson, B. L.; Dauskardt, R. H.; Karunadasa, H. I. Broadband Emission with a Massive Stokes Shift from Sulfonium $\mathrm{Pb}-\mathrm{Br}$ Hybrids Chem. Mater. 2017, 29, 70837087.

[56] Yangui, A.; Pillet, S.; Lusson, A.; Bendeif, E. E.; Triki, S.; Abid, Y.; Boukheddaden, K. Control of the white-light emission in the mixed two-dimensional hybrid perovskites $\left(\mathrm{C}_{6} \mathrm{H}_{11} \mathrm{NH}_{3}\right)_{2}\left[\mathrm{PbBr}_{4-\mathrm{x}} \mathrm{I}_{\mathrm{x}}\right]$ Journal of Alloys and Compounds 2017,699, 1122.

[57] Barkaoui, H.; Abid, H.; Yangui, A.; Triki, S.; Boukheddaden, K.; Abid, Y. Yellowish White-Light Emission Involving Resonant Energy Transferin a New One-Dimensional Hybrid Material: $\left(\mathrm{C}_{9} \mathrm{H}_{10} \mathrm{~N}_{2}\right) \mathrm{PbCl}_{4}$ J. Phys. Chem. C 2018, 122, 24253-24261.

[58] Yangui, A.; Pillet, S.; Bendeif, E. E.; Lusson, A.; Triki, S.; Abid, Y.; Boukheddaden, K. Broadband Emission in a New Two-Dimensional Cd-based Hybrid Perovskite ACS Photonics 2018, 5(4), 1599.

[59] Roccanova, R.; Houck, M.; Yangui, A.; Han, D.; Shi, H.; Wu,Y.; Glatzhofer, D. T.; Powell, D. R.; Chen, S.; Fourati, H.; Lusson, A.; Boukheddaden, K.; Du, M. H.; Saparov, B. Broadband Emission in Hybrid Organic-Inorganic Halides of Group12 Metals ACS Omega 2018, 3, 18791-18802. 
[60] Peng, C.; Zhuang, Z.; Yang, H.; Zhang, G.; Fei, H. Ultrastable, cationic threedimensional leadbromide frameworks that intrinsically emit broadband white-light Chem. Sci. 2018, 9, 1627-1633.

[61] Peng, Y.; Yao, Y.; Li, L.; Wu, Z.; Wang, S.; Luo, J. White-light emission in a chiral onedimensional organic-inorganic hybrid perovskite Journal of Materials Chemistry C 2018 6(22), 6033-6037.

[62] Wang, S.; Yao, Y.; Wu, Z.; Peng, Y.; Li, L.; Luo, J. Realization of "warm” white light via halide substitution in polartwo-dimensional hybrid perovskites $\left(2 \mathrm{meptH} \mathrm{H}_{2}\right) \mathrm{PbCl}_{\mathrm{x}} \mathrm{Br}_{4-\mathrm{x}} J$. Mater. Chem. C 2018, 6(45), 12267-12272.

[63] Wu, G.; Zhou, C.; Ming, W.; Han, D.; Chen, S.; Yang, D.; Besara, T.; Neu, J.; Siegrist, T.; Du, M. H.; Ma, B.; Dong, A. A One-Dimensional Organic Lead Chloride Hybrid with Excitation-Dependent Broadband Emissions ACS Energy Lett. 2018, 3, 1443-1449.

[64] Wu, Z.; Ji, C.; Sun, Z.; Wang, S.; Zhao, S.; Zhang, W.; Li, L.; Luo, J. Broadband whitelight emission with a highcolor rendering index in a two-dimensional organic-inorganic hybrid perovskite J. Mater. Chem. C 2018, 6, 1171-1175.

[65] Ji, C.; Wang, S.; Li, L.; Sun, Z.; Hong, M.; Luo, J. The First 2D Hybrid Perovskite Ferroelectric Showing Broadband White-Light Emission with High Color Rendering Index Adv. Funct. Mater. 2018, 1805038.

[66] Yangui, A.; Roccanova, R.; Wu, Y.; Du, M. H.; Saparov, B. Highly Efficient BroadBand Luminescence Involving Organic and Inorganic Molecules in a Zero-Dimensional Hybrid Lead Chloride J. Phys. Chem. C 2019, 123, 22470-22477.

[67] Yangui, A.; Roccanova, R.; McWhorter, T. M.; Wu, Y. ; Du, M. H. ; Saparov, B. Hybrid Organic-Inorganic Halides $\left(\mathrm{C}_{5} \mathrm{H}_{7} \mathrm{~N}_{2}\right)_{2} \mathrm{MBr}_{4}(\mathrm{M}=\mathrm{Hg}$, $\mathrm{Zn})$ with High Color Rendering Index and High-Efficiency White-Light Emission Chem. Mater. 2019, 31, 2983-2991.

[68] Gautier, R.; Massuyeau, F.; Galnon, G.; Paris, M. Lead Halide Post-Perovskite-Type Chains for High-Efficiency White-Light Emission Adv. Mater. 2019, 31, 1807383.

[69] Shang, M.; Li, C.; Lin, J. How to produce white light in a single-phase host? Chem. Soc. Rev., 2014, 43, 1372.

[70] Robinson, K.; Gibbs, G. V.; Ribbe, P. H. Quadratic Elongation: A Quantitative Measure of Distortion in Coordination Polyhedra Science 1971, $172 \mathrm{~N}^{\circ} 3983,567-570$.

[71] Li, Y. Y.; Lin, C. K.; Zheng, G. L.; Cheng, Z. Y.; You, H.; Wang, W. D.; Lin, J. Novel $\langle 110\rangle$ Oriented Organic-Inorganic Perovskite Compound Stabilized by N-(3Aminopropyl)imidazole with Improved Optical Properties Chem. Mater. 2006, 18, 34633469.

[72] Trabelsi, S.; Samet, A.; Dammak, H.; Michaud, F., Santos, L.; Abid, Y.; Chaabouni, S. Optical properties of a new luminescent hybrid material $\left[\mathrm{C}_{6} \mathrm{~N}_{2} \mathrm{H}_{5}\right]_{3} \mathrm{BiCl}_{6}$ involving a resonance energy transfer (RET) Optical Materials 2019, 89, 355-360.

[73] Liu, Z. F.; Wu, M. F.; Wang, S. H.; Zheng, F. K.; Wang, G. E.; Chen, J.; Xiao, Y.; Wu, A. Q.; Guo, G. C.; Huang, J. S.; $\mathrm{Eu}^{3+}$-doped $\mathrm{Tb}^{3+}$ metal-organic frameworks emitting tunable three primary colors towards white light J. Mater. Chem. C 20131, 4634-3639.

[74] Wei, Y.; Li, Q.; Sa, R.; Wu, K. A white-light-emitting LnMOF with color properties improved via $\mathrm{Eu}^{3+}$ doping: analternative approach to a rational designfor solid-state lighting Chem. Commun. 2014, 50, 1820-1823. 
[75] Hong, X.; Ishihara, T.; Nurmikko, A. V. Dielectric confinement effect on excitons in PbI4-based layered semiconductors Phys. Rev. B 1992, 45, 12, 6961-6964.

[76] Jiang, D. S.; Jung, H.; Ploog, K. Temperature dependence of photoluminescence from GaAs single andmultiple quantum well heterostructures grown by molecular beam epitaxy $J$. Appl. Phys. 1988, 64, 1371-1377.

[77] Gauthron, K.; Lauret, J. S.; Doyennette, L.; Lanty, G.; AlChoueiry, A.; Zhang, S. J.; Brehier, A.; Largeau, L.; Mauguin, O.; Bloch, J.; Deleporte, E. Optical spectroscopy of twodimensional layered $\left(\mathrm{C}_{6} \mathrm{H}_{5} \mathrm{C}_{2} \mathrm{H}_{4}-\mathrm{NH}_{3}\right)_{2}-\mathrm{PbI}_{4}$ perovskite OPTICS EXPRESS 2010,18, 6, 59125919.

[78] Ishihara, T.; Takahashi, J.; Goto, T. Optical properties due to electronic transitions in two-dimensional semiconductors $\left(\mathrm{C}_{\mathrm{n}} \mathrm{H}_{2 \mathrm{n}+1} \mathrm{NH}_{3}\right)_{2} \mathrm{PbI}_{4}$ Phys. Rev. B 1990, 42, 17, 11099-11107.

[79] Yangui, A.; Pillet, S.; Mlayah, A.; Lusson, A.; Bouchez, G.; Triki, S.; Abid, Y.; Boukheddaden, K. Structural phase transition causing anomalous photoluminescence behavior inperovskite $\left(\mathrm{C}_{6} \mathrm{H}_{11} \mathrm{NH}_{3}\right)_{2}\left[\mathrm{PbI}_{4}\right]$ J. Chem. Phys. 2015,143, 224201, 1-11.

[80] Lee, J.; Koteles, E. S.; Vassell, M. O. Luminescence linewidths of excitons in GaAs quantum wells below $150 \mathrm{~K}$ Phys. Rev. B 1986, 33, 8, 5512-5516. 


\section{Table of Contents Use Only}

White light emission from a zero-dimensional lead-chloridehybrid material

Slim Elleuch, ${ }^{*}$ Alain Lusson, Sebastien Pillet, Kamel Boukheddaden, and Younes Abid

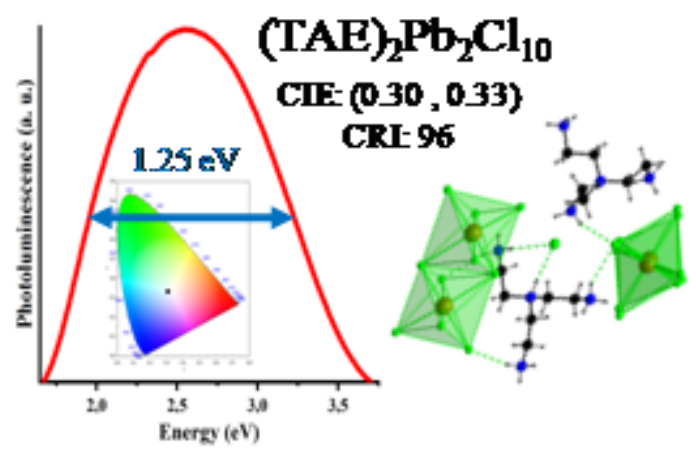

